\title{
Chapter 10 \\ Multi-dimensional Subjective Wellbeing and Lone Parenthood Following Divorce in Flanders (Northern Belgium)
}

\author{
Sam Jenkinson, Hideko Matsuo, and Koenraad Matthys
}

\begin{abstract}
This study contributes to the literature on the relationship between subjective wellbeing (SWB), divorce, gender, and lone parenthood. We use the cross sectional Divorce in Flanders Survey (2009), comparing divorced, single parents to married parents, and also to each other across genders. Our results confirm the lower levels of SWB reported by divorced, single parents. This is true across multiple dimensions of SWB, including measures of life satisfaction, emotional wellbeing and vitality. Our results highlight the lower wellbeing reported by divorced, single parents in relation to the residential status of children below the age of 18 . This is the case for both mothers and fathers, but fathers with non-residential children below 18 reported lower life satisfaction, whereas for the equivalent mothers, emotional wellbeing was diminished. We find little evidence of gender differences between lone mothers and fathers who report residential children. This suggests that the "intensive motherhood" hypothesis, which predicts that parenting may affect the SWB of mothers more negatively than fathers, may operate differently in the case of single vs. married parents.
\end{abstract}

Keywords Divorce · Multidimensional subjective wellbeing · Gender · Lone parenting

\subsection{Introduction}

Divorced, single parents report lower levels of subjective wellbeing (SWB) than parents who are partnered. This pattern, observed repeatedly in the research literature, may be grounded in the double burden of parenting and work experienced by divorced, single parents. Generally these parents have lower economic and parenting resources, including time and energy, all of which can impact the quality of their

S. Jenkinson $(\bowtie) \cdot$ H. Matsuo $\cdot$ K. Matthys

KU Leuven, Leuven, Belgium

e-mail: sam.jenkinson@kuleuven.be; hideko.matsuo@kuleuven.be; koenraad.matthys@

kuleuven.be 
lives. Important intergenerational implications may follow to the extent that their situation negatively influences the wellbeing, and socio-economic and psychological outcomes of their children in comparison to children from families with more parenting resources (Amato 2000, 2001; Amato and Keith 1991).

Previous research findings on the relationships between partnership, parenting, gender and the different dimensions of SWB are quite nuanced. Parenting alone following divorce may result in a greater difficulty combining work and family life and an increased risk of poverty, which for women is both higher and more likely to persist until re-partnership (Brady and Burroway 2012; Jansen et al. 2009; Lewin and Stier 2018; Maldonado and Nieuwenhuis 2015). Single parenthood has been linked to a higher likelihood of illness and depression for women in the post-divorce period, and also later in life (Baronowska-Rataj et al. 2014; Cairney et al. 2006; Cooper et al. 2008; Meadows 2009). In addition, men generally experience greater declines in overall health, subjective wellbeing, measures of satisfaction with family life and greater feelings of loneliness and isolation following a divorce than do women, although this pattern is not universal (Dykstra and Fokkema 2007; Leopold 2018; Leopold and Kalmijn 2016; Shor et al. 2012; Stack and Eshleman 1998). Both men and women, therefore, experience the impact of divorce, but in different ways over various aspects of wellbeing. What is needed, however, is an approach which examines comparisons of gender, partnership, parenting and also different measures of SWB.

Our study takes this multi-dimensional approach, by comparing male and female divorcees with each other and with married parents. The main research question guiding this analysis concerns how divorced, single parents differ in terms of SWB when compared to married parents and taking into account the residential status of children under 18. The contribution of this research is twofold. Firstly, by incorporating multiple dimensions of SWB, including life satisfaction, emotional wellbeing, and vitality, we overcome the tendency in prior studies to focus on single item measures. This can mask important gendered associations with multidimensional SWB. Secondly, we provide compelling evidence of how SWB varies in relation to partnership and parenthood status, including differences between residential and non-residential children, using different dimensions of SWB following a divorce. ${ }^{1}$

\subsection{Research Background}

\subsubsection{Multi-dimensional Measures of Subjective Wellbeing}

Recent debates concerning subjective wellbeing have emphasised the need to broaden the focus beyond single item measures of happiness and life satisfaction (Michaelson et al. 2009). The argument is that prior studies have adopted the same

\footnotetext{
${ }^{1}$ We analyze single parents following divorce only and do not consider those entering single parenthood via widowhood, fertility outside of marriage or the dissolution of a cohabiting union.
} 
few measures, which may be too theoretically narrow. We define subjective wellbeing in line with the OECD guidelines as "Good mental states, including all of the various evaluations, positive and negative, that people make of their lives and the affective reactions of people to their experiences" (OECD 2013, p. 10). This definition draws predominantly from the work of Diener et al. (2006) and also Thomson and Marks (2008). It is intentionally broad, in order to include all dimensions of subjective wellbeing.

These dimensions include: evaluative SWB (cognitive), hedonic SWB (affective) and eudemonia (flourishing) (Clark and Senik 2011; Thomson and Marks 2008). We define life evaluation, or life satisfaction, as "a reflective assessment on a person's life, or some specific aspect of it" (OECD 2013, p. 10). Affect is "a person's feelings or emotional states, typically measured with reference to a particular point in time" (OECD 2013, p. 10) and eudemonia "a sense of meaning and purpose in life, or good psychological functioning” (OECD 2013, p. 10).

\subsubsection{Multi-dimensional Subjective Wellbeing, Gender and Partnership Status}

\subsubsection{Life Satisfaction}

One of our measures is a typical cognitive measure of SWB, life satisfaction. The findings from research regarding the association between life satisfaction, gender, and divorce are nuanced. Studies have shown that generally, women are more likely to report lower levels of life satisfaction than men (Blanchflower and Oswald 2004; Herbst and Ifcher 2012; Stevenson and Wolfers 2009), while in studies on life satisfaction following divorce, men have been shown to be more negatively affected than women (Andress and Bröckel 2007; Leopold 2018). This decline for men occurs at the same time as deteriorations in overall health, subjective wellbeing, and measures of satisfaction with family life. However, this decline is temporary, with levels of life satisfaction usually recovering to pre-divorce levels within 5 years and on par with those of divorced women (Leopold 2018).

One of the reasons for this gender difference may be that women are better at adapting to their post-divorce circumstances (Brinig and Allen 2000; Kalmijn and Poortman 2006; Leopold 2018). Studies examining SWB and divorce have shown that women appear to emotionally accept the end of a marriage at an earlier stage. This is reflected in the greater likelihood of women to initiate the divorce proceedings. Compared to men, women are more likely to experience greater psychological upheaval in the period leading up to a divorce, rather than its aftermath.

Hypothesis 1: Given that both men and women experience declines in life satisfaction following a divorce, we expect those who are divorced and remaining single to report lower levels of life satisfaction than those who are married. In addition, we expect this gap to be greater for divorced, single men. 


\subsubsection{Emotional Wellbeing}

The measure of hedonic SWB we use in this study is emotional wellbeing. No studies that we are aware of have examined the relationship between emotional wellbeing specifically and partnership status. Studies using hedonic measures of SWB, such as happiness, have generally found that being partnered has a positive contribution (Dolan et al. 2008; Kohler et al. 2005). In these studies, those who are married had higher levels of happiness than those who are divorced and/or single.

With regards to gender differences and hedonic measures of SWB, research has shown that men and women usually report comparable levels on items similar to emotional wellbeing (Dolan et al. 2008; Louis and Zhao 2002). However, this was not the case for some hedonic measures of SWB, such as affect, that uses contrasting measures of the frequency of positive vs negative feelings. Studies using these measures have generally shown more extreme associations for women on individual items, which are balanced out in overall or composite measures (Comstock and Helsing 1976; Fujita et al. 1991; Gurin et al. 1960).

Hypothesis 2: We expect those who are divorced and also single to have lower emotional wellbeing than those who are married. In addition, given the evidence concerning hedonic measures of SWB similar to emotional wellbeing, we expect no gender differences concerning measures of emotional wellbeing.

\subsubsection{Vitality}

We examine eudemonic SWB with a measure of vitality. To our knowledge, there are no studies that have closely examined vitality in relation to gender and partnership status. Previous studies using eudemonic measures similar to vitality to examine the impact of gender and partnership status have produced differing results across different measures.

Vitality is a composite measure, which includes one item of self-rated health (SRH). Details of other items included can be seen in Table 10.1. Studies of gendered differences in SRH have shown that women typically are more likely to report lower SRH than men (Jylhä et al. 1998; McFadden et al. 2009; Oksuzyan et al. 2010; Wu et al. 2012). Related concepts include physical activity and capability. Studies looking at differences in levels of movement found men to be much more active than women, with implications for health and vitality $(7.7 \mathrm{~h}$ per week vs 4.0$)$ (Hull et al. 2010). In contrast to this, more recent research examining self-rated health within the labour market has found that men are more likely to report lower SRH than women (Taloyan et al. 2015). Furthermore, Ryff (2014) reviewed the correlates of several eudemonia measures that include SRH, and found that those who are single, or experienced a divorce, reported lower SWB than those who did not and, additionally, that this lower SWB was more pronounced for women than for men. 
Table 10.1 Subjective wellbeing: item questions

\begin{tabular}{l|l|l}
\hline Question & Scale & Meaning \\
\hline Life satisfaction (cognitive) & $0-10$ & $\begin{array}{l}0=\text { extremely unsatisfied } \\
10=\text { extremely satisfied }\end{array}$ \\
\hline $\begin{array}{l}\text { On the whole, how satisfied are you with } \\
\text { your life? }\end{array}$ & &
\end{tabular}

\section{Emotional wellbeing (hedonic)}

\begin{tabular}{|c|c|c|}
\hline How often have you felt...during the last week? & & \\
\hline Happy & $1-4$ & $1=$ rarely $4=$ all of the time \\
\hline Enjoyed life & $1-4$ & $1=$ rarely $4=$ all of the time \\
\hline Sad & $1-4$ & $1=$ rarely $4=$ all of the time \\
\hline Depressed & $1-4$ & $1=$ rarely $4=$ all of the time \\
\hline \multicolumn{3}{|l|}{ Vitality (eudemonic) } \\
\hline \multicolumn{3}{|l|}{ How often have you felt...during the last week? } \\
\hline Everything was an effort & $1-5$ & $1=$ rarely $4=$ all of the time \\
\hline My sleep was restless & $1-5$ & $1=$ rarely $4=$ all of the time \\
\hline I could not get going & $1-5$ & $1=$ rarely $4=$ all of the time \\
\hline How would you rate your health? & $1-5$ & $1=$ very bad $5=$ excellent \\
\hline I see myself as someone who is full of energy & $1-5$ & $1=$ agree $5=$ disagree \\
\hline
\end{tabular}

Hypothesis 3: Based on the findings of the more comprehensive review study, which looked at overall correlates of eudemonia measures (Ryff 2014), we expect those who are divorced to report lower levels of vitality than those who are married, and that this will have a greater impact on women.

\subsubsection{Multi-dimensional Subjective Wellbeing, Lone Parenting and Gender}

Across most industrialised nations lone mothers face a number of obstacles following a divorce, which might be detrimental to their SWB. This includes a greater risk of poverty than their married counterparts, single fathers and single childless women (Brady and Burroway 2012; Maldonado and Nieuwenhuis 2015). In light of this, whilst it may be expected that these obstacles would indicate that lone mothers are likely to report lower levels of SWB than married mothers, some studies looking specifically at hedonic measures of SWB have found no negative association between parenting alone and SWB among mothers (Baronowska-Rataj et al. 2014). This study also provided qualitative evidence of a positive association between lone motherhood and eudemonic SWB, with children providing a sense of purpose and meaning for mothers (Ibid). Moreover, a study looking at another eudemonic measure of SWB, perceived parenting energy, found little difference between single and married mothers (Janisse et al. 2009).

Conversely, research looking at measures of happiness over a 20-year period shows a persistent and statistically significant gap between single and married 
mothers, though overall levels of SWB for single mothers had increased throughout the period (Herbst and Ifcher 2012). Furthermore, recent cross national research looking at life satisfaction has shown that lone mothers still report lower levels of SWB in comparison to married mothers (Pollmann-Schult 2018). Likewise, a study examining both lone mothers' and fathers' SWB, found both to be at an elevated risk of psychological distress in comparison to married parents (Collings et al. 2014). This risk was also found to be worse for lone mothers (Ibid).

Hypothesis 4: (4.1) Based on the findings presented from previous literature, we expect lone mothers to report lower levels of both life satisfaction and (4.2) emotional wellbeing than married mothers. Concerning vitality, however, in light of the studies which examined parenting in relation to eudemonic measures of SWB, (4.3) we expect no differences between lone mothers and married mothers concerning levels of vitality. Considering the aforementioned research examining psychological distress, which examined both men and women (Collings et al. 2014), (4.4) we expect lone fathers to report lower levels of SWB than married fathers across all dimensions.

\subsubsection{Lone Parenting and Gender}

While the lower levels of SWB of lone parents in comparison to married parents may be self-evident, why lone parents differ across gender is not entirely clear. However, some empirical research suggests that this is due to gender differences in the pressures and importance placed on the parenting role. The importance placed on the parenting role is increasingly something that in a number of ways differentially affects fathers and mothers. Research has highlighted how men's physical activity declines significantly following the birth of a child (Hull et al. 2010). In comparison to previous generations, fathers feel pressure to spend more time with their children in order to identify as a good father, and this identity is increasingly important to their sense of wellbeing (Milkie et al. 2010; Nomaguchi et al. 2005; Townsend 2002). This importance of fatherhood is reflected in the declines in life satisfaction they experience following a divorce (Leopold 2018). Divorced fathers experience increased feelings of loneliness, isolation and declines in measures of satisfaction with family life, with much of it caused by their separation from children, who are more likely to reside with their mother (Dykstra and Fokkema 2007; Leopold and Kalmijn 2016; Shor et al. 2012; Stack and Eshleman 1998).

Conversely, some scholars argue that ideals of fatherhood are not as central to men's SWB as motherhood is to women's. Thus while fatherhood is increasingly important to men, it is still only one of several important gender roles expectations, such as breadwinner and husband (Dykstra and Keizer 2009; Milkie et al. 2010; Townsend 2002). Mothers typically face additional parenting responsibilities following the birth of a child, such as changes to a mother's lifestyle, profession, and hours of employment (Cinamon and Rich 2002; Hynes and Clarkberg 2005; Sanchez and Thomson 1997). The additional pressures are identified as potential reasons why mothers report lower levels of subjective wellbeing than fathers, including 
during activities with their children (Musick et al. 2016; Ryff 2014). Moreover, motherhood has been linked to greater risks of fatigue and psychological distress, both in comparison to fathers and non-mothers (Simon 1992; Reichl et al. 2014). These extra challenges and pressures experienced by mothers have been termed "intensive motherhood" (Christopher 2012; Hays 1996; Singh 2004). "Intensive motherhood" is a cultural model that mothers prescribe to as one of many potentially competing ideals (such as a good employee) (Christopher 2012). In a study examining how these competing ideals may affect how married and single mothers perform motherhood, Christopher (2012) found that married mothers, in trying to balance work and motherhood, behaved in a way she describes as "extensive motherhood" (Christopher 2012). They felt the pressures associated with "intensive motherhood", but expressed it through how they were in charge. These pressures linked with intensive motherhood were, however, not so clearly displayed by single mothers. They stated greater wishes to work, regardless of need, and a refusal to sacrifice themselves "to the point of nothingness" (Christopher 2012, pp. 87).

Hypothesis 5: With regard to parental gender differences in SWB we have a number of expectations based on the preceding literature. (5.1) We expect divorced, single fathers to report lower levels of life satisfaction than divorced, single mothers. Furthermore, we expect this to be worse for divorced fathers who do not reside with their children at all. Though some research has pointed to a lack of gender differences in relation to hedonic measures of SWB, broader research concerning parenting and SWB has generally pointed towards a greater negative association with motherhood than fatherhood. Thus, (5.2) we expect lone mothers to report lower levels of SWB than lone fathers when analysing measures of emotional wellbeing and vitality.

\subsection{Data, Measures and Methods}

\subsubsection{Data}

We analyze data from the cross sectional "Divorce in Flanders survey" (Mortelmans et al. 2011) collected in 2009/10. The sample contains couples married between January 1st, 1971 and December 31st, 2008. All couples resided in the Flemish region and have Belgian nationality, though their parents may be non-Belgian. All respondents are currently in their first marriage, or have experienced one divorce. The age range of the sample is 22-72 years. The years of divorce range from 1974 up until 2009. The survey is an intergenerational dataset (i.e. grandparents, parents and children) drawn from the Belgian national register. The response rate is $42.2 \%$. This is similar to other European multi-actor surveys (Dykstra et al. 2005). The data is cross-sectional and starts from a selected reference marriage, which is either intact $(n=1811)$ or divorced $(n=4659)$. The sample was over-selected with respect to marriages ending in divorce, such that $1 / 3$ of the original sample involved intact marriages, and 2/3 divorced ones. The sample was also stratified with regards to the year of marriage (Mortelmans et al. 2011). 


\subsubsection{Measures}

\subsubsection{Dependent Variables of Multi-dimensional Subjective Well-Being}

We use multiple SWB items to create composite measures. These items pose theoretically similar questions to respondents. This method has been demonstrated to improve the accuracy of responses by averaging out any errors or mistakes by respondents (Krueger and Schkade 2008; Michaelson et al. 2009) and is an established practice for the assessment of wellbeing. Examples and evaluations of these methods are reported in Thomson and Marks (2008), Clark and Senik (2011), Dolan et al. (2008).

We transform values of all items so that positive and negative items are in the same direction. These are then centred and aggregated to make composite indicators of SWB (Thomson and Marks 2008; Michaelson et al. 2009; Clark and Senik 2011). Centring the items makes the aggregation simpler. The robustness of this method for constructing wellbeing measures is assessed in Clark and Senik (2011).

The resulting indicators tap each of the aforementioned dimensions of SWB (Table 10.1). We use a traditional single item measure of life satisfaction (cognitive/ evaluative). Life satisfaction is captured on a $0-10$ scale and is centred. Our measure of emotional wellbeing is constructed following Michaelson et al. (2009). It consists of 4 items; two of the items involve the frequency of positive emotions and two involve negative emotions all of which are scored on a 1-4 scale. (Michaelson et al. 2009). For our measure of eudemonia, we use a composite measure of vitality. It includes questions capturing a subjective assessment of energy levels, feeling "well rested" and feeling healthy and active. Each of these items is scored on a 1-5 scale (Michaelson et al. 2009). All items are centred. ${ }^{2}$

\subsubsection{Independent Variables}

Our main independent variable has 9 categories representing all combinations of partnership and parental status and one residual category (Table 10.2). Partnership status is distinguished between those who were still in their first marriage at the time of the survey and those who were divorced and not yet re-partnered by the time of the survey (single). Parental status distinguishes between those with resident children (below age 18), those with non-resident children, and those who are childless. Household residency was established from a question on, who was present in the house at least 4 days per week, or in cases where parents had divorced, at least some of the time on a regular basis in an ordinary week. For those who are divorced

\footnotetext{
${ }^{2}$ Statistical indicators for the composite measures of SWB are reported in appendix one, including Pearson correlations and Cronbach's Alpha. Cronbach's Alpha indicates that the internal consistency could not be improved by the removal of any of the items included in both of the composite measures.
} 


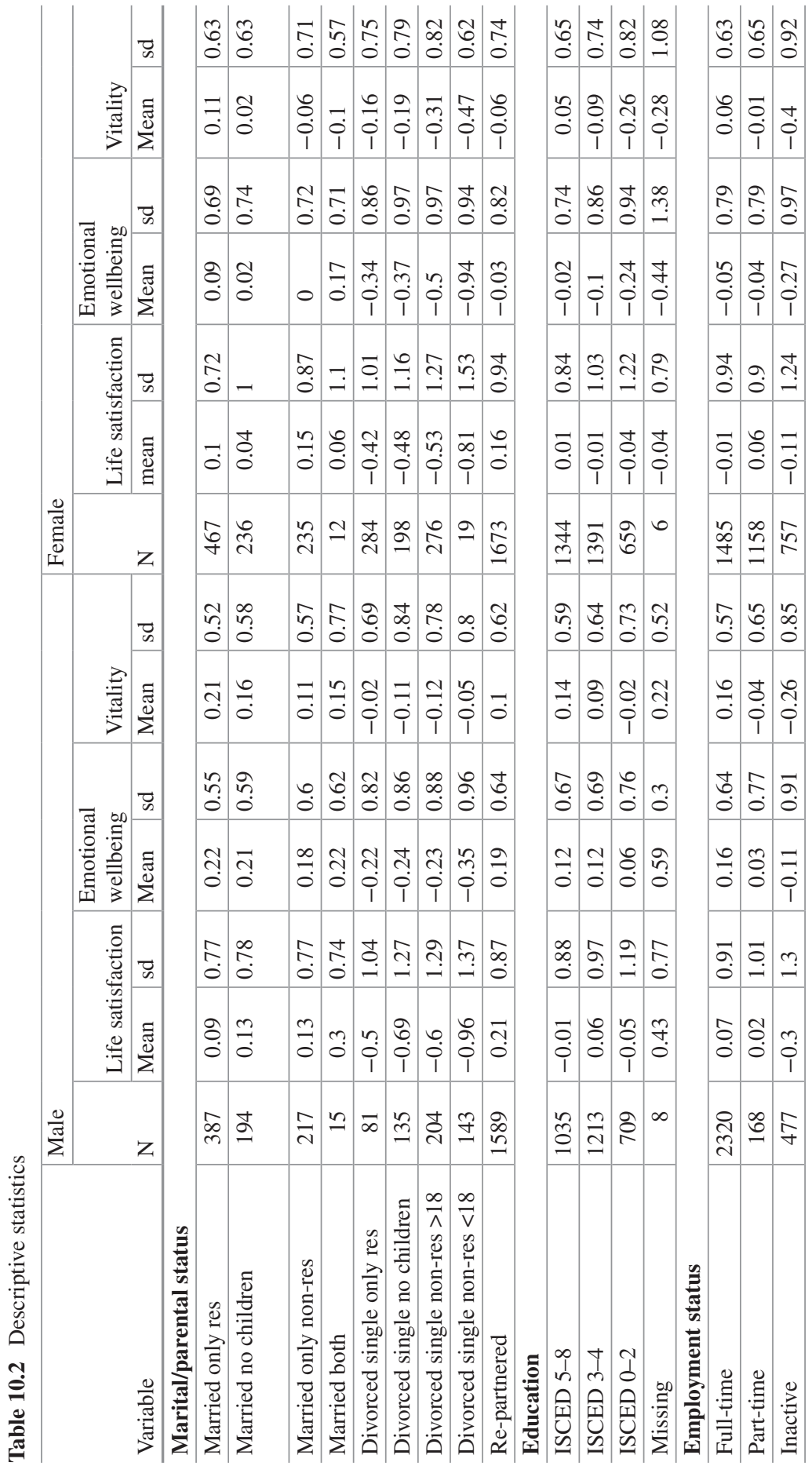




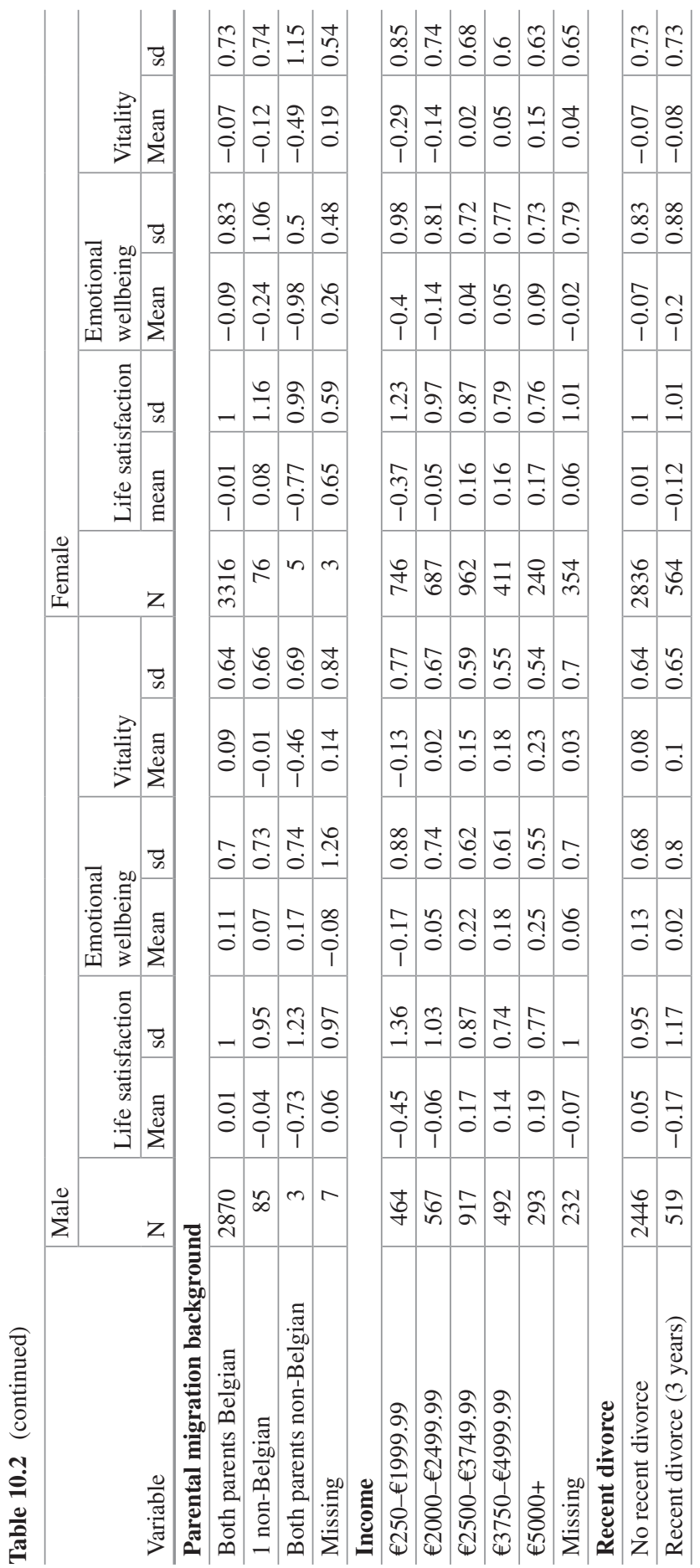


and also single, we make a distinction by the age of non-resident children. ${ }^{3}$ Respondents were asked the ages and number of non-resident children who live outside of the household. Respondents with a child under the age of 18 are in a separate category from those with adult children who have left the home because this distinction is likely to be relevant for SWB. We expect those with non-resident children younger than age 18 to report lower SWB than those with older children who have left the home. The number of cases for this group is lower for women than for men. This distinction is not required for those who are married, as the number of cases is extremely low and is not the focus of the current analysis. The category "married both" refers to those who have both residential children and non-residential children. In this scenario it refers to children over the age of 18 who have left the home. Those categorised as having no children reported that they had no children resident in the home and did not indicate that they had any children, of any age, living outside of the home. "Re-partnered" refers to those who have divorced prior to the survey but are no longer single. They have re-partnered via either a living apart together (LAT) relationship, cohabitating union or through re-marriage.

Our analysis includes several socio-economic and demographic control variables. We use covariates for age and a second-degree polynomial of age as well as a categorical variable for the migration background of parents. Education is operationalised as a categorical variable by ISCED score across three levels. Employment status is specified as three categories; inactive, part time and full time. Monthly household income is a categorical variable with 5 levels, representing incomes below €2000, €2000-€2499, €2500-€3749, €3750-€4999 and €5000+. The occurrence of a recent divorce is specified as a dummy indicator capturing whether the event occurred in the preceding 3 years. Descriptive statistics for all of variables are presented in Table 10.2, separately for females and males. ${ }^{4}$

\subsubsection{Methods}

Statistical models of the three SWB indicators are estimated using ordinary least squares regression, separately for men and women. Additionally, models are estimated including both genders, to directly compare such categories as divorced lone mothers vs. lone fathers.

The benefit of this approach is to illuminate the differences between parents by marital status, but also between lone parents by gender. The models are unweighted and we use $\mathrm{p}<0.05$ to evaluate statistical significance.

\footnotetext{
${ }^{3}$ We have chosen to separate the child residency variable by the age of children. This is to prevent the mixing of different expected associations (adult children who have left the home, children under 18 but are no longer home because of a new custody arrangement, and those who have no children). In some cases this leads to categories with a low number of cases, however due to the theoretical distinctions in the associations we expect from these different categories, we believe this is an important separation to make.

${ }^{4}$ Missing values for the independent variables are categorised as separate levels in each categorical variable and can be seen in Table 10.2.
} 


\subsection{Results}

The results presented in Tables 10.3, 10.4, and 10.5 show the OLS estimates for life satisfaction, emotional wellbeing and vitality respectively. Column M1 shows the OLS estimations for marital and parental statuses. The reference category consists of respondents who are married with resident children. Column M2 reports the OLS estimates when all the control variables are incorporated. The results presented in Table 10.6 apply to the combined female and male subsamples and show estimates for each dimension of SWB for those who are both divorced and single, combining both genders. Column M1 shows coefficients for people who are divorced and also single by gender and child residential situation. The reference category is divorced, single mothers with resident children. Column M2 includes the model estimates following the introduction of control variables into the models, as in Tables 10.3, 10.4 and 10.5 .

Regarding partnership status, the estimates presented in Table 10.3 show that divorced, single men and women, regardless of parental situation, report lower life satisfaction than those who are married. Concerning parenthood status, being a divorced, single father is negatively related to life satisfaction in comparison to married fathers $(\beta=-0.59, \mathrm{p}<0.001 ; \beta=-0.43, \mathrm{p}<0.001$ Table 10.3, M1, M2). This is also the case when comparing divorced, single mothers to married mothers $(\beta=-0.52, \mathrm{p}<0.001 ; \beta=-0.33, \mathrm{p}<0.001$ Table 10.3, M1, M2). Additionally, the estimates indicate that divorced, single fathers with non-resident children below the age of 18 have the lowest life satisfaction of all groups $(\beta=-1.05, \mathrm{p}<0.001$; $\beta=-0.85, \mathrm{p}<0.001$ Table 10.3, M1, M2). The gap between divorced, single fathers with non-resident children below the age of 18 and married fathers is also larger than the gap for the equivalent estimates for mothers $(\beta=-0.91, \mathrm{p}<0.001$; $\beta=-0.64, \mathrm{p}<0.001$ Table 10.3, M1, M2).

All of these negative coefficients presented in Table 10.3 are sensitive to the addition of control variables, with the magnitude of coefficients generally diminishing. The direction of the educational coefficients are different for men and women. The estimates for education show that men with ISCED scores of $0-2$ and 3-4 had higher levels of life satisfaction than those with scores of $5-6(\beta=0.13, \mathrm{p}<0.01$; $\beta=0.13, \mathrm{p}<0.01$ Table 10.3, M2), whereas the gradient is reversed for women. Likewise, economic inactivity is only negatively associated with the life satisfaction of men $(\beta=-0.29, \mathrm{p}<0.001$, Table $10.3, \mathrm{M} 2)$ and is statistically insignificant for women. For men the incidence of a divorce in the last 3 years is negative, whereas the same estimate is statistically insignificant for women $(\beta=-0.10, p<0.05$ Table 10.3, M2).

In Table 10.4 we find that all divorced and single categories have lower emotional wellbeing than those who are married and that this is true for both men and women. With regard to the different parenthood statuses, we find that divorced, single fathers report lower emotional wellbeing in comparison to married fathers $(\beta=-0.44, \mathrm{p}<0.001 ; \beta=-0.34, \mathrm{p}<0.001$ Table 10.4, M1, M2). We also find lower levels of SWB when comparing divorced, single mothers to married mothers 
Table 10.3 OLS estimates of life satisfaction

\begin{tabular}{|c|c|c|c|c|}
\hline \multirow[t]{2}{*}{ Life satisfaction } & \multicolumn{2}{|l|}{ Male } & \multicolumn{2}{|l|}{ Female } \\
\hline & M1 & M2 & M1 & M2 \\
\hline Coefficients: & Estimate & Estimate & Estimate & Estimate \\
\hline (Intercept) & $0.09(0.05)$ & $1.75(0.47) * * *$ & $0.10(0.04) *$ & $1.71(0.43) * * *$ \\
\hline \multicolumn{5}{|c|}{ Marital/parental status (ref - married with residential children) } \\
\hline Married no children & $0.04(0.08)$ & $0.05(0.08)$ & $-0.06(0.08)$ & $-0.02(0.08)$ \\
\hline Married only non-res & $0.04(0.08)$ & $0.14(0.09)$ & $0.05(0.08)$ & $0.16(0.9)$ \\
\hline Married both & $0.21(0.25)$ & $0.23(0.25)$ & $-0.04(0.28)$ & $0.10(0.28)$ \\
\hline $\begin{array}{l}\text { Divorced single only } \\
\text { res }\end{array}$ & $-0.59(0.11) * * *$ & $-0.43(0.12) * * *$ & $-0.52(0.07) * * *$ & $-0.33(0.08) * * *$ \\
\hline $\begin{array}{l}\text { Divorced single no } \\
\text { children }\end{array}$ & $-0.78(0.09) * * *$ & $-0.58(0.10) * * *$ & $-0.58(0.08) * * *$ & $-0.35(0.09) * * *$ \\
\hline $\begin{array}{l}\text { Divorced single } \\
\text { non-res }>18\end{array}$ & $-0.69(0.08) * * *$ & $-0.48(0.09) * * *$ & $-0.63(0.07) * * *$ & $-0.37(0.09) * * *$ \\
\hline $\begin{array}{l}\text { Divorced single } \\
\text { non-res }<18\end{array}$ & $-1.05(0.09) * * *$ & $-0.85(0.10) * * *$ & $-0.91(0.23) * * *$ & $-0.64(0.23) * *$ \\
\hline Re-partnered & $0.12(0.05) *$ & $0.19(0.06) * *$ & $0.06(0.05)$ & $0.15(0.05) * *$ \\
\hline \multicolumn{5}{|c|}{ Education (ref - ISCED 5-6) } \\
\hline ISCED 3-4 & & $0.13(0.04) * *$ & & $0.01(0.04)$ \\
\hline ISCED 0-2 & & $0.13(0.05) * *$ & & $0.06(0.05)$ \\
\hline $\begin{array}{l}\text { Age (years } \\
\text { continuous) }\end{array}$ & & $-0.09(0.02) * * *$ & & $-0.08(0.02) * * *$ \\
\hline Age $* 2$ & & $0.00(0.00) * * *$ & & $0.00(0.00) * * *$ \\
\hline \multicolumn{5}{|c|}{ Labour supply (ref - full time emp) } \\
\hline Part-time & & $-0.05(0.08)$ & & $0.07(0.04)$ \\
\hline Inactive & & $-0.29(0.06) * * *$ & & $-0.03(0.05)$ \\
\hline \multicolumn{5}{|c|}{ Parental migration background (ref - both Belg) } \\
\hline 1 non-Belgian & & $-0.05(0.10)$ & & $0.13(0.11)$ \\
\hline $\begin{array}{l}\text { Both parents } \\
\text { non-Belgian }\end{array}$ & & $-0.50(0.54)$ & & $-0.70(0.43)$ \\
\hline \multicolumn{5}{|c|}{ Income (ref - €0-€1999) } \\
\hline$€ 2000-€ 2499.99$ & & $0.16(0.06) * *$ & & $0.20(0.05) * * *$ \\
\hline$€ 2500-€ 3749.99$ & & $0.23(0.06) * * *$ & & $0.30(0.05) * * *$ \\
\hline$€ 3750-€ 4999.99$ & & $0.19(0.07) * *$ & & $0.29(0.07) * * *$ \\
\hline$€ 5000+$ & & $0.27(0.08) * * *$ & & $-0.32(0.08) * * *$ \\
\hline $\begin{array}{l}\text { Recent divorce } \\
3 \text { years }\end{array}$ & & $-0.10(0.05) *$ & & $-0.03(0.05)$ \\
\hline $\mathbf{N}$ & 2708 & 2708 & 3285 & 3285 \\
\hline Adjusted r-squared & 0.12 & 0.14 & 0.07 & 0.08 \\
\hline
\end{tabular}

Signif. codes: ‘ $* * *$ ’ 0.001 '**' 0.01 ‘*’ 0.05

Note: "Other" refers to those who have divorced but are no longer single. "Married both" refers to those who have both residential children and non-residential children over 18 who have left the home 
Table 10.4 OLS estimates of emotional wellbeing

\begin{tabular}{|c|c|c|c|c|}
\hline \multirow[t]{2}{*}{ Emotional wellbeing } & \multicolumn{2}{|l|}{ Male } & \multicolumn{2}{|l|}{ Female } \\
\hline & M1 & M2 & M1 & M2 \\
\hline Coefficients: & Estimate & Estimate & Estimate & Estimate \\
\hline (Intercept) & $0.22(0.03) * * *$ & $1.22(0.34) * * *$ & $0.009(0.04) *$ & $1.61(0.36) * * *$ \\
\hline \multicolumn{5}{|c|}{ Marital/parental status (ref - married residential children) } \\
\hline Married no children & $-0.02(0.06)$ & $-0.01(0.06)$ & $-0.07(0.07)$ & $-0.05(0.07)$ \\
\hline $\begin{array}{l}\text { Married only } \\
\text { non-res }\end{array}$ & $-0.05(0.06)$ & $0.02(0.06)$ & $-0.09(0.07)$ & $0.00(0.07)$ \\
\hline Married both & $0.00(0.18)$ & $0.02(0.18)$ & $0.08(0.24)$ & $0.24(0.24)$ \\
\hline $\begin{array}{l}\text { Divorced single only } \\
\text { res }\end{array}$ & $-0.44(0.08) * * *$ & $-0.34(0.09) * * *$ & $-0.43(0.06) * * *$ & $-0.27(0.07) * * *$ \\
\hline $\begin{array}{l}\text { Divorced single no } \\
\text { children }\end{array}$ & $-0.47(0.07) * * *$ & $-0.34(0.07) * * *$ & $-0.46(0.07) * * *$ & $-0.28(0.08) * * *$ \\
\hline $\begin{array}{l}\text { Divorced single } \\
\text { non-res }>18\end{array}$ & $-0.45(0.06) * * *$ & $-0.31(0.07) * * *$ & $-0.59(0.06) * * *$ & $-0.39(0.07) * * *$ \\
\hline $\begin{array}{l}\text { Divorced single } \\
\text { non-res }<18\end{array}$ & $-0.57(0.07) * * *$ & $-0.43(0.07) * * *$ & $-1.03(0.19) * * *$ & $-0.76(0.19) * * *$ \\
\hline Re-partnered & $-0.03(0.04)$ & $0.01(0.04)$ & $-0.12(0.04) * *$ & $-0.03(0.05)$ \\
\hline \multicolumn{5}{|c|}{ Education (ref - ISCED 5-6) } \\
\hline ISCED 3-4 & & $0.05(0.03)$ & & $-0.02(0.03)$ \\
\hline ISCED 0-2 & & $0.06(0.04)$ & & $-0.09(0.04) *$ \\
\hline $\begin{array}{l}\text { Age (years } \\
\text { continuous) }\end{array}$ & & $-0.05(0.01) * * *$ & & $-0.08(0.02) * * *$ \\
\hline Age $* 2$ & & $0.00(0.00) * * *$ & & $0.00(0.00) * * *$ \\
\hline \multicolumn{5}{|c|}{ Labour supply (ref - full time emp) } \\
\hline Part-time & & $-0.12(0.05) *$ & & $0.00(0.03)$ \\
\hline Inactive & & $-0.22(0.04) * * *$ & & $-0.17(0.04) * * *$ \\
\hline
\end{tabular}

Parental migration background (ref - both Belg)

\begin{tabular}{l|l|c|l|l}
\hline 1 non-Belgian & $-0.04(0.07)$ & & $-0.10(0.09)$ \\
\hline $\begin{array}{l}\text { Both parents } \\
\text { non-Belgian }\end{array}$ & $0.16(0.39)$ & & $-0.86(0.36) *$ \\
\hline
\end{tabular}

Income (ref - €0-€1999)

\begin{tabular}{l|l|c|l|l}
\hline$€ 2000-€ 2499.99$ & & $0.10(0.04) *$ & & $0.14(0.05) * *$ \\
\hline$€ 2500-€ 3749.99$ & & $0.17(0.04) * * *$ & & $0.22(0.05) * * *$ \\
\hline$€ 3750-€ 4999.99$ & & $0.13(0.05) *$ & & $0.21(0.06) * * *$ \\
\hline$€ 5000+$ & & $0.21(0.06) * * *$ & & $0.23(0.07) * * *$ \\
\hline $\begin{array}{l}\text { Recent divorce } \\
\text { 3 years }\end{array}$ & & $-0.03(0.04)$ & & $-0.04(0.04)$ \\
\hline $\mathbf{N}$ & 2708 & 2708 & 3284 & 3284 \\
\hline Adjusted r-squared & 0.06 & 0.08 & 0.05 & 0.07 \\
\hline
\end{tabular}

Signif. codes: ‘ $* * *$ ’ 0.001 '**’ 0.01 '*' 0.05

Note: "Other" refers to those who have divorced but are no longer single. "Married both" refers to those who have both residential children and non-residential children over 18 who have left the home 
Table 10.5 OLS estimates of vitality

\begin{tabular}{|c|c|c|c|c|}
\hline \multirow{3}{*}{$\begin{array}{l}\text { Vitality } \\
\text { Coefficients: }\end{array}$} & \multicolumn{2}{|l|}{ Male } & \multicolumn{2}{|l|}{ Female } \\
\hline & M1 & M2 & M1 & M2 \\
\hline & Estimate & Estimate & Estimate & Estimate \\
\hline (Intercept) & $0.21(0.03) * * *$ & $1.12(0.32) * * *$ & $0.11(0.03) * * *$ & $1.09(0.32) * * *$ \\
\hline \multicolumn{5}{|c|}{ Marital/parental status (ref - married resident children) } \\
\hline Married no children & $-0.05(0.06)$ & $-0.02(0.06)$ & $-0.09(0.06)$ & $-0.08(0.06)$ \\
\hline Married only non-res & $-0.10(0.05)$ & $0.03(0.06)$ & $-0.18(0.06) * *$ & $-0.04(0.06)$ \\
\hline Married both & $-0.06(0.17)$ & $-0.03(0.17)$ & $-0.21(0.21)$ & $0.02(0.21)$ \\
\hline $\begin{array}{l}\text { Divorced single only } \\
\text { res }\end{array}$ & $-0.23(0.08) * *$ & $-0.16(0.08) *$ & $-0.28(0.05) * * *$ & $-0.20(0.06) * * *$ \\
\hline $\begin{array}{l}\text { Divorced single no } \\
\text { children }\end{array}$ & $-0.32(0.06) * * *$ & $-0.17(0.07) *$ & $-0.30(0.06) * * *$ & $-0.18(0.7) * *$ \\
\hline $\begin{array}{l}\text { Divorced single non } \\
\text { res }>18\end{array}$ & $-0.34(0.06) * * *$ & $-0.15(0.06) *$ & $-0.42(0.06) * * *$ & $-0.28(0.06) * * *$ \\
\hline $\begin{array}{l}\text { Divorced single } \\
\text { non-res }<18\end{array}$ & $-0.26(0.06) * * *$ & $-0.13(0.07)$ & $-0.58(0.17) * * *$ & $-0.37(0.17) *$ \\
\hline Re-partnered & $-0.11(0.04) * *$ & $-0.06(0.04)$ & $-0.17(0.04) * * *$ & $-0.11(0.04) * *$ \\
\hline \multicolumn{5}{|c|}{ Education (ref - ISCED score 5-6) } \\
\hline ISCED 3-4 & & $0.00(0.03)$ & & $-0.06(-0.03) *$ \\
\hline ISCED 0-2 & & $-0.03(0.03)$ & & $-0.14(0.04) * * *$ \\
\hline Age & & $-0.05(0.01) * * *$ & & $-0.05(0.01) * *$ \\
\hline Age $* 2$ & & $0.00(0.00) * * *$ & & $0.00(0.00) * * *$ \\
\hline \multicolumn{5}{|c|}{ Labour supply (ref - full time emp) } \\
\hline Part-time & & $-0.21(0.05) * * *$ & & $-0.07(0.03) *$ \\
\hline Inactive & & $-0.42(0.04) * * *$ & & $-0.42(0.04) * * *$ \\
\hline \multicolumn{5}{|c|}{ Parental nationality (ref - both Belg) } \\
\hline 1 non-Belgian & & $-0.06(0.07)$ & & $0.00(0.08)$ \\
\hline $\begin{array}{l}\text { Both parents } \\
\text { non-Belgian }\end{array}$ & & $-0.49(0.36)$ & & $-0.36(0.31)$ \\
\hline \multicolumn{5}{|c|}{ Income (ref - €0-€1999) } \\
\hline$€ 2000-€ 2499.99$ & & $0.03(0.04)$ & & $0.03(0.04)$ \\
\hline$€ 2500-€ 3749.99$ & & $0.10(0.04) *$ & & $0.11(0.04) * *$ \\
\hline$€ 3750-€ 4999.99$ & & $0.10(0.05) *$ & & $0.08(0.05)$ \\
\hline$€ 5000+$ & & $0.15(0.05) * *$ & & $0.17(0.06) * *$ \\
\hline $\begin{array}{l}\text { Recent divorce } \\
3 \text { years }\end{array}$ & & $0.04(0.03)$ & & $0.04(0.04)$ \\
\hline $\mathbf{N}$ & 2666 & 2666 & 3247 & 3247 \\
\hline Adjusted r-squared & 0.02 & 0.08 & 0.02 & 0.09 \\
\hline
\end{tabular}

Signif. codes: ‘***’ 0.001 ‘**’ 0.01 ‘*’ 0.05

Note: "Other" refers to those who have divorced but are no longer single. "Married both" refers to those who have both residential children and non-residential children over 18 who have left the home 


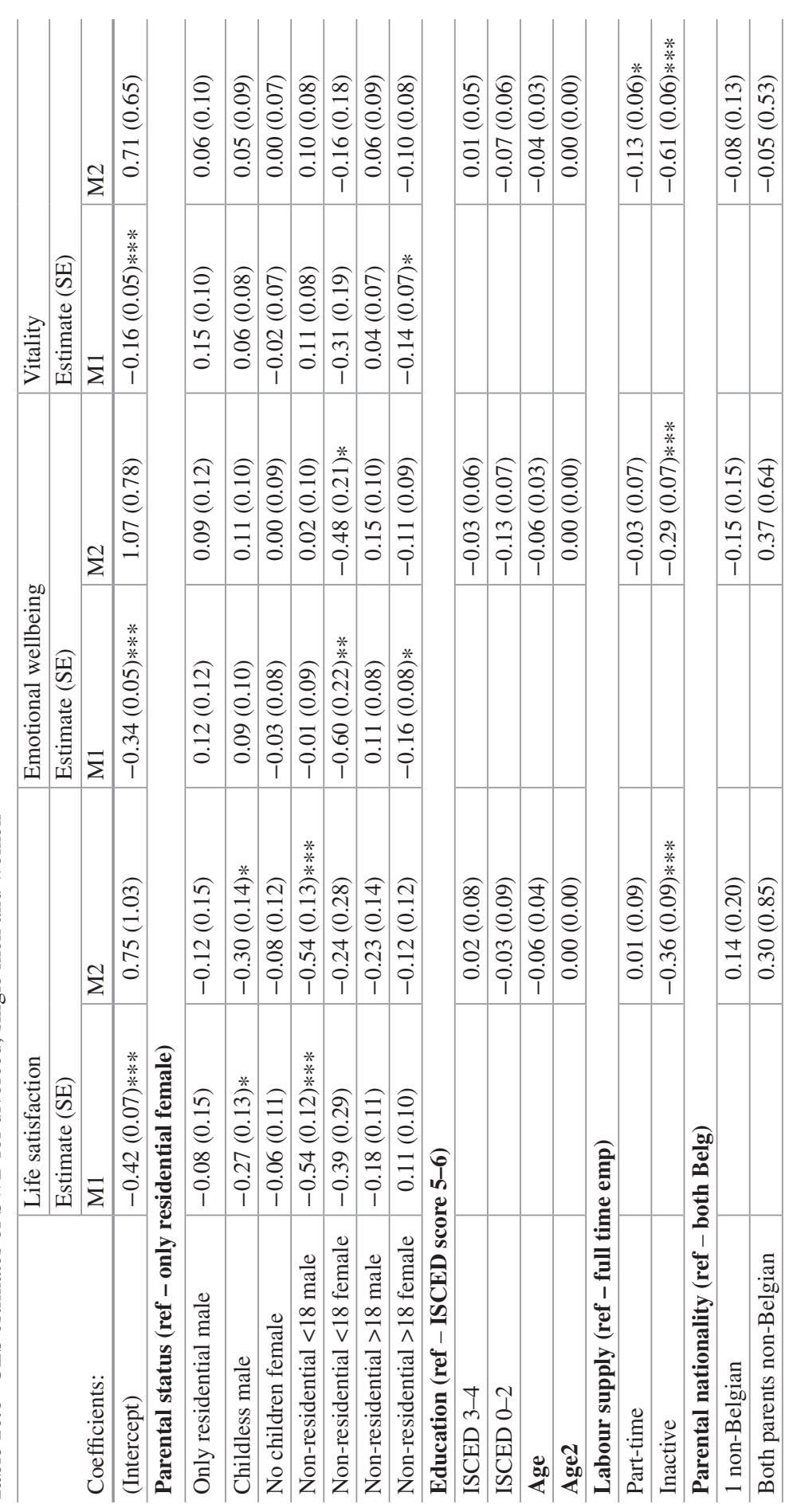




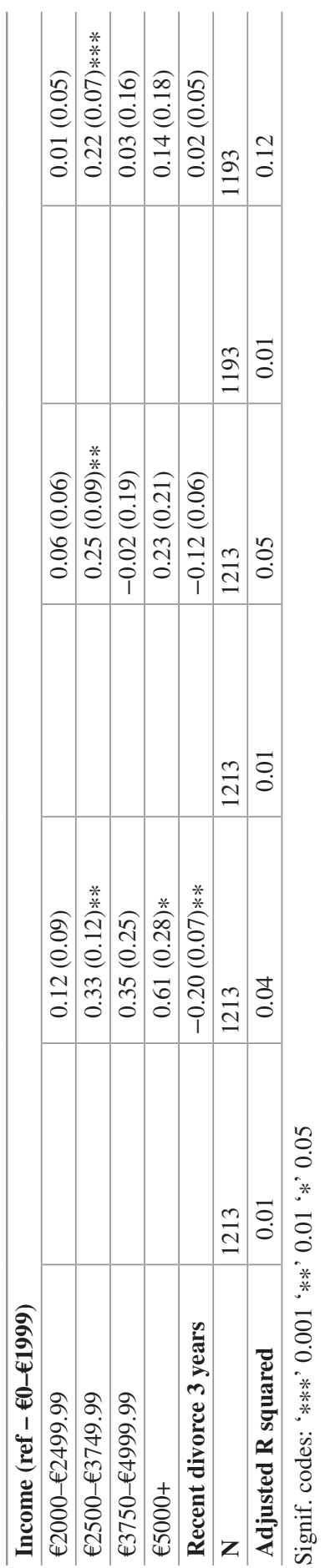


$(\beta=-0.43, \mathrm{p}<0.001 ; \beta=-0.27, \mathrm{p}<0.001$ Table 10.4, M1, M2). For women the largest negative estimate for SWB is found for divorced, single mothers with nonresident children below the age of 18 and emotional wellbeing $(\beta=-1,03, p<0.001$, Table 10.4, M1; $\beta=-0.76, \mathrm{p}<0.001$, Table 10.4, M2). Furthermore, this difference in emotional wellbeing is also larger than the corresponding one for divorced, single fathers with non-resident children below the age of 18 (Male; $\beta=-0.57, \mathrm{p}<0.001$, Table 10.4, M1; $\beta=-0.43, \mathrm{p}<0.001$, Table 10.4, M1. Female; $\beta=-1,03, \mathrm{p}<0.001$, Table 10.4, M1; $\beta=-0.76, \mathrm{p}<0.001$, Table 10.4, M2).

The negative estimates presented in Table 10.4 for emotional wellbeing are also sensitive to the additional variables included in M2. The coefficients presented for education show small differences, however they are not statistically significant. Women with the lowest levels of education, ISCED scores 0-2 and 3-4, have the lowest levels of emotional wellbeing, however only those at the lowest levels are statistically significant $(\beta=-0.09, \mathrm{p}<0.05$, Table 10.4 , M2). For emotional wellbeing, economic inactivity is negatively associated with the life satisfaction of men and women $(\beta=-0.22, \mathrm{p}<0.001 ; \beta=-0.17, \mathrm{p}<0.001$ Table 10.4, M2), although part-time working is only associated negatively with the emotional wellbeing of men $(\beta=-0.12, \mathrm{p}<0.05$ Table 10.4, M2). The estimated effect of a divorce in the previous 3 years is not statistically significant for either gender.

In Table 10.5 we find that nearly all groups for single divorcees have lower vitality than those who are married. The differences in estimates of vitality between married parents and parents who are single divorcees is considerably larger for women than for men. This is not the case for estimates of divorced, single men with resident children below the age of 18 , which following the introduction of control variables, becomes statistically insignificant. Likewise, married women with nonresident children report lower levels of vitality $(\beta=-0.18, \mathrm{p}<0.01$; Table 10.5, M1), although it also becomes statistically insignificant once control variables are included in the models. We find that divorced, single father's report lower vitality than married fathers $(\beta=-0.23, \mathrm{p}<0.01 ; \beta=-0.16, \mathrm{p}<0.05$ Table 10.5, M1, M2). This is also true for the comparison between divorced, single mothers and married mothers $(\beta=-0.28, \mathrm{p}<0.001 ; \beta=-0.20, \mathrm{p}<0.001$ Table 10.5, M1, M2). The coefficient for divorced, single fathers with non-resident children below the age of 18 is also negative, although it becomes statistically insignificant in M2 when control variables are introduced into the models $(\beta=-0.26, \mathrm{p}<0.001$; Table 10.5, M1). This is not the case for divorced, single mothers with non-resident children below the age of 18 , where both estimates are negative and statistically significant $(\beta=-0.58, \mathrm{p}<0.001 ; \beta=-0.37, \mathrm{p}<0.5$ Table $10.5, \mathrm{M} 1, \mathrm{M} 2)$.

The coefficients presented in Table 10.5 for vitality are also reduced in magnitude with the additional variables included in M2. Women with the lower levels of education, ISCED scores $0-2$ and $3-4$, have the lowest levels of vitality $(\beta=-0.14$, $\mathrm{p}<0.001 ; \beta=-0.06, \mathrm{p}<0.05$, Table 10.5, M2). The educational coefficients for men are negative for ISCED scores of $0-2$, although they are not statistically significant. For both genders, vitality declines with age $(\beta=-0.05, \mathrm{p}<0.001 ; \beta=-0.05$, $\mathrm{p}<0.01$ Table $10.5, \mathrm{M} 2)$ and is associated positively with higher incomes. In addition, economic inactivity is negatively associated with vitality of both genders 
$(\beta=-0.42, \mathrm{p}<0.001 ; \beta=-0.42, \mathrm{p}<0.001$ Table $10.5, \mathrm{M} 2)$. This is also the case for those who work part-time $(\beta=-0.21, \mathrm{p}<0.001 ; \beta=-0.07, \mathrm{p}<0.05$ Table 10.5, M2). The estimate for the occurrence of a recent divorce is statistically insignificant for both genders.

The results displayed in Table 10.6 indicate that there are no statistically significant gender differences between divorced, single parents with resident children. Concerning those with non-resident children below the age of 18 , the results for life satisfaction reveal that divorced, single fathers have the lowest life satisfaction when compared to divorced, single mothers $(\beta=-0,54, \mathrm{p}<0.001$, Table 10.6, M1; $\beta=-0.54, \mathrm{p}<0.001$, Table 10.6, M2). None of the estimates for fathers with nonresidential children below the age of 18 are statistically significant for either emotional wellbeing or vitality. Divorced, single mothers with non-resident children have lower emotional wellbeing than those with resident children. This is true of divorced mothers with children above the age of $18(\beta=-0,16, p<0.05$, Table 10.6), but also particularly those with children under the age of $18(\beta=-0,60, \mathrm{p}<0.01$, Table 10.6, M1; $\beta=-0.48, \mathrm{p}<0.05$, Table $10.6, \mathrm{M} 2)$. The life satisfaction results for divorced, single mothers with non-resident children below the age of 18 are not statistically significant. For vitality, divorced, single mothers with non-resident children below the age of 18 are shown to have lower levels of vitality than lone mothers with resident children $(\beta=-0,14 \mathrm{p}<0.05$, M1; Table 10.6), however the coefficient becomes insignificant once control variables are introduced into the models.

In Table 10.6 the incidence of a divorce in the last 3 years is negative and statistically significant for life satisfaction $(\beta=-0.20, \mathrm{p}<0.01$ Table 10.6, M2), though it is statistically insignificant for emotional wellbeing and vitality. We consistently find that economic inactivity is negatively associated with each dimension of SWB and is particularly strong for vitality $(\beta=-0.36, \mathrm{p}<0.001 ; \beta=-0.29, \mathrm{p}<0.001$ M1; Table 10.6; $\beta=-0.61, \mathrm{p}<0.001$ Table 10.6, M2).

These results have highlighted that across multiple dimensions of SWB, divorced, single mothers and fathers have lower SWB in comparison to married parents. We also found no differences by gender between lone mothers and fathers with resident children. They have also shown that divorced, single mothers and fathers with nonresident children under age 18 have the lowest levels of SWB. This was also dependent on the dimension of SWB being studied. The impact of non-resident children below the age of 18 is more negative for men when studying items of life satisfaction (Table 10.6). This is not the case for divorced, single women, for whom the negative impact of non-resident children below the age of 18 is more pronounced for emotional wellbeing (Table 10.6).

\subsection{Discussion}

The results which we have presented here have largely confirmed our expectations concerning hypotheses one to four that single divorcees in general, but also lone parents specifically, have lower levels of life satisfaction, emotional wellbeing and vitality than those who are married. We did not find evidence in support of hypoth- 
esis 5 that the SWB of lone parents with resident children varies by gender, but differences in SWB were found in relation to non-residential children. In line with the previous literature, our findings for life satisfaction (H. 1) show that divorced, single men with non-resident children below the age of 18 report the lowest estimates, but these are also sensitive to the incidence of a recent divorce (Andress and Bröckel 2007; Leopold and Kalmijn 2016; Leopold 2018). This was not the case for women, where the life satisfaction estimate for a recent divorce was not statistically significant. Our findings for emotional wellbeing (H. 2) are also in line with studies which have examined partnership status in relation to other hedonic measures of SWB, such as happiness (Dolan et al. 2008; Kohler et al. 2005). The results for vitality (H. 3) are also consistent with previous findings for eudemonic measures of SWB (Ryff 2014), indicating that the differences between those married and those who are single divorcees is larger for mothers than for fathers. Concerning hypothesis four and parenthood specifically, our results have shown that single parents, following a divorce, are more likely to be (H. 4.1) less satisfied with their lives, (H. 4.2) experience a greater frequency of negative emotions than positive ones, and to feel (H. 4.3) less vigour for their daily lives, in terms of perceptions of their energy levels and overall health. Concerning hypothesis 4.3 , our results are in contrast to previous literature in finding differences in levels of vitality reported by married and single parents. More broadly, these conclusions are in line with previous research (Baronowska-Rataj et al. 2014; Collings et al. 2014; Dykstra and Keizer 2009; Pollmann-Schult 2018). It is, however, striking for both its consistency across multiple dimensions of SWB, and also by gender.

We fail to find evidence in support of gender differences (H. 5.1, H. 5.3) in the SWB of lone mothers and fathers, specifically in the case of those with resident children. The literature concerning intensive motherhood argues for gender differences in the SWB of parents, however in the case of lone parents with resident children, we fail to find evidence to support this. This is perhaps suggestive of the ways that the pressures associated with parenting may manifest somewhat more unequally within a marriage, but in a manner more congruent with a traditional marital division of parenting labour. In the case of lone parents, however, both men and women may feel those parenting pressures in a more similar fashion.

We find little evidence of gender differences between lone parents with residential children, however, these findings are in line with the literature concerning hedonic measures of SWB, such as emotional wellbeing and happiness (Dolan et al. 2008; Louis and Zhao 2002). One argument as to the cause of this inconsistency has been called gender differences in affect intensity (Fujita et al. 1991). This means that men and women may report similar levels of overall happiness, but women typically report higher frequency of both positive and negative emotions. These greater values for explicitly positive or negative emotions are therefore balanced out in overall measures. We did find that the largest negative estimate for SWB is found for divorced, single mothers with non-resident children below the age of 18 and emotional wellbeing. We also found that this difference in emotional wellbeing is larger than the corresponding deficit for divorced, single fathers with non-resident children under the age of 18 , however these models are separated by gender and so 
are not directly comparable. Moreover, when comparing men and women specifically within the same model (Table 10.6), we find little evidence for gender differences in emotional well-being between divorced, single parents with resident children.

We did, nevertheless, find evidence of a negative impact of non-residential children below the age of 18 on life satisfaction in models that did make comparisons by gender. Our results partially confirmed hypothesis 5.1 that divorced fathers who are still single experience the lowest levels of life satisfaction, although only in the case of those with non-residential children below the age of 18 . This is indicative of the potential centrality of contact with children in how fathers evaluate their lives. These findings are in line with previous literature on the association between lower life satisfaction, divorce and the changes in living arrangements between fathers and non-resident children below the age of 18 (Andress and Bröckel 2007; Leopold 2018; Leopold and Kalmijn 2016). However, this pattern did not hold for the emotional wellbeing and vitality outcomes, with no statistically significant coefficient for men with non-resident children below the age of 18 . In the case of mothers, we find the largest differences in SWB between divorced, single mothers with nonresident children below the age of 18 , when compared to divorced, single mothers with resident children. For each of these groups, the numbers of cases are relatively low, especially for mothers. We advise caution with respect to the stability of these results until further research can replicate or disconfirm them.

These differences by gender in relation to the particular dimension of SWB examined, when analysing specifically the impact of non-resident children below the age of 18 amongst single parents, underpin the importance of considering the multidimensionality of SWB. For men, the experience of a recent divorce and separation from children may negatively impact life satisfaction, but not other dimensions of SWB. It does not appear to be associated with a greater likelihood of experiencing negative emotions or lower vitality. For divorced, single mothers with non-resident children below the age of 18, a different pattern emerges. They show a greater likelihood of experiencing a higher frequency of negative emotions, when compared to divorced, single mothers with resident children below the age of 18 .

It is worth noting that the lower levels of SWB reported by the divorced and single were strongly mediated by controls for socio-economic characteristics for income, employment and education. This suggests clear benefits of work and employment for the SWB of parents. It also points to avenues of further research regarding the employment choices available to lone parents, the benefits of each and what factors may mediate these choices.

The data we have used here is cross sectional, which presents several limitations for the substantive interpretation of the model estimates. For instance, we are unable to control for unobserved characteristics potentially correlated with both lower levels of wellbeing and divorce. We are also unable to monitor the differences of adaptation over time to partnership and parenting states, which is known to be an important explanatory factor of gender differences in wellbeing (Leopold 2018). Another limitation concerns the geographical (regional) reach of our database, which is limited to the region of Flanders. Furthermore, our analysis is also restricted 
only to those who ever marry, with no more than one divorce and excludes those entering lone parenthood through any avenue other than marital dissolution. Our findings apply only to people who fall within these criteria. This is important because people adhering to less egalitarian norms may be more likely to enter into marriage, rather than cohabiting unions. These traditional values may be associated with how much partnership dissolution and parenting alone impact SWB.

Future research on this topic should investigate lone parenthood using longitudinal data to address the cross-sectional limitations of our study. This would allow for a better assessment of causality by controlling for unobserved characteristics, which may be correlated with both divorce and SWB. In addition, a cross national perspective would allow for a broader assessment of how factors such as family (e.g. custodial arrangements/regulations) and welfare state/labour market policies (e.g work and family life balance policies) attenuate or aggravate the associations discussed here. Finally we need larger samples of divorced, single fathers, both with and without residential children, for the analytical power necessary to address these gender specific research questions.

\subsection{Conclusion}

In this study we have examined the association between gender, partnership, lone parenthood following divorce and subjective wellbeing. Taking a gender focused approach and using the cross-sectional Divorce in Flanders Survey (2009), we compared divorced, single parents to married parents, and also to each other. Our analytical approach acknowledged the multidimensionality of SWB by examining indicators of life satisfaction (cognitive), emotional wellbeing (hedonic) and vitality (eudemonic). The results we have presented confirm the positive association between partnership and SWB on one hand, and the negative one between divorce, single parenthood and SWB on the other. This is true across all dimensions of SWB, including measures of life satisfaction, emotional wellbeing and vitality. Our results have also shown the detrimental impact of having non-residential children below the age of 18 on SWB. This is true for both lone mothers and lone fathers, but with important differences by the dimension of SWB analysed. Lone fathers with nonresidential children below 18 reported lower life satisfaction, whereas for lone mothers it was emotional wellbeing. In terms of how lone parenting with residential children impacts subjective wellbeing by gender, we find little evidence of differences between lone mothers and fathers across multiple measures of SWB. This is in contrast to research relating to "intensive motherhood", which predicts that parenting may affect the SWB of mothers more negatively than fathers.

This research contributes to the literature regarding the relationship between divorce and the lower levels of SWB reported by divorced, single parents. It documents in considerable detail the quality of life of these parents, their lower satisfaction with their lives, their experiencing a greater frequency of negative than positive emotions and their feeling of lower vitality. The gender specific negative impact of non-residential children below the age of 18 , and how this varies across different 
dimensions of SWB is an also interesting avenue for future research. Moreover, these results raise important questions regarding the wellbeing, socio-economic and psychological outcomes of children from these families (Amato 2000, 2001; Amato and Keith 1991). Unhappy lone parents, facing the double burden of work and family life, are unlikely to have the same amount of parenting resources, such as time and energy, as married parents. These challenges are critical and may carry intergenerational implications. Thus, a vital question for future research concerns how lower levels of SWB may relate to changes in parenting practices; and how this may impact children of different ages. Because we live in societies with high levels of marital dissolution, and growing numbers of parents experiencing periods of lone parenthood, answers to these questions becomes more imperative.

Acknowledgement This project has received funding from the European Union Horizon 2020 research and innovation program under the Marie Sklodowska-Curie grant no 676060. The authors would like to thank the three reviewers, Matthijs Kalmijn, Amit Kaplan, Gert Thielemans and the editor Dimitri Mortelmans, for their valuable comments and suggestions. We would also like to thank Gray Swicegood for valuable comments on previous versions. This chapter further benefited from the support of the Centre for Population, Family and Health (CPFH) at the University of Antwerp and the Flemish Agency of Innovation and Entrepreneurship (Grant number: 140069), which enabled Open Access to this chapter.

\section{Appendix}

\section{Pairwise Pearson Correlations Emotional Wellbeing \& Alpha Cr}

\begin{tabular}{l|l|l|l|l}
\hline & Depression & Sadness & Enjoyment & Happy \\
\hline Depression & 1.000 & & & \\
\hline Sadness & 0.598 & 1.000 & & \\
\hline Enjoyment & 0.394 & 0.411 & 1.000 & \\
\hline Happy & 0.434 & 0.453 & 0.618 & 1.000 \\
\hline Alpha Cr. & 0.790 & & & \\
\hline
\end{tabular}

\section{Pairwise Pearson Correlations Vitality \& Alpha Cr}

\begin{tabular}{l|l|l|l|l|l}
\hline & Health & Energy & Restless & Get going & Effort \\
\hline Health & 1.000 & & & & \\
\hline Energy & 0.328 & 1.000 & & & \\
\hline Restless & 0.311 & 0.177 & 1.000 & & \\
\hline Get going & 0.361 & 0.333 & 0.378 & 1.000 & \\
\hline Effort & 0.385 & 0.317 & 0.385 & 0.623 & 1.000 \\
\hline Alpha Cr. & 0.737 & & & & \\
\hline
\end{tabular}




\section{References}

Amato, P. R. (2000). The consequences of divorce for adults and children. Journal of Marriage and Family, 62(4), 1269-1287.

Amato, P. R. (2001). Children of divorce in the 1990s: An update of the Amato and Keith (1991) meta-analysis. Journal of Family Psychology, 15(3), 355.

Amato, P. R., \& Keith, B. (1991). Parental divorce and the Well-being of children: A meta-analysis. Psychological Bulletin, 110(1), 26.

Andress, H., \& Bröckel, M. (2007). Income and life satisfaction after marital disruption in Germany. Journal of Marriage and Family, 69, 500-512.

Baronowska-Rataj, A., Matysiak, A., \& Monika, M. (2014). How does lone motherhood decrease women's happiness? Evidence from qualitative and quantitative research. Journal of Happiness Studies, 15, 1457-1477.

Blanchflower, D. G., \& Oswald, A. J. (2004). Well-being over time in Britain and the USA. Journal of Public Economics, 88(7-8), 1359-1386.

Brady, D., \& Burroway, R. (2012). Targeting, universalism, and single-mother poverty: A multilevel analysis across 18 affluent democracies. Demography, 49(2), 719-746.

Brinig, M. F., \& Allen, D. W. (2000). These boots are made for walking: Why most divorce filers are women. American Law and Economics Review, 2, 126-169.

Cairney, J., Pevalin, D., \& Wade, T. (2006). Twelve-month psychiatric disorder among single and married mothers: The role of marital history. Canadian Journal of Psychiatry, 51, 671-676.

Christopher, K. (2012). Extensive mothering: Employed mothers' constructions of the good mother. Gender \& Society, 26(1), 73-96.

Cinamon, R. G., \& Rich, Y. (2002). Gender differences in the importance of work and family roles: Implications for work-family conflict. Sex Roles, 47(11-12), 531-541.

Clark, A., \& Senik, C. (2011). Is happiness different from flourishing? Cross country evidence from the ESS. Revue d'économie politique, 121, 17-31.

Collings, S., Jenkin, G., Carter, K., \& Signal, L. (2014). Gender differences in the mental health of single parents: New Zealand evidence from a household panel survey. Social Psychiatry and Psychiatric Epidemiology, 49(5), 811-821.

Comstock, G. W., \& Helsing, K. J. (1976). Symptoms of depression in two communities. Psychological Medicine, 6, 551-555.

Cooper, C., et al. (2008). Depression and common mental disorders in lone parents: Results of the 2000 National Psychiatric Morbidity Survey. Psychological Medicine, 38(3), 335-342.

Diener, E., Lucas, R. E., \& Napa Scollon, C. (2006). Beyond the hedonic treadmill: Revising the adaptation theory of well-being. American Psychologist, 61(4), 305-314.

Dolan, P., Peasgood, T., \& White, M. (2008). Do we really know what makes us happy? A review of the economic literature on the factors associated with subjective well-being. Journal of Economic Psychology, 29(1), 94-122.

Dykstra, P. A., \& Fokkema, T. (2007). Social and emotional loneliness among divorced and married men and women: Comparing the deficit and cognitive perspectives. Basic and Applied Social Psychology, 29(1), 1-12.

Dykstra, P., \& Keizer, R. (2009). The wellbeing of childless men and fathers in midlife. Ageing and Society, 29, 1227-1242.

Dykstra, P. A., Kalmijn, M., \& Knijn, T. C. (2005). Codebook of the Netherlands Kinship Panel Study: A multi-actor, multi-method panel study on solidarity in family relationships. Netherlands Kinship Panel Study.

Fujita, F., Diener, E., \& Sandvik, E. (1991). Gender differences in negative affect and well-being: The case for emotional intensity. Journal of Personality and Social Psychology, 61(3), 427-434.

Gurin, G., Veroff, J., \& Feld, S. (1960). Americans view their mental health: A nationwide interview survey. New York: Basic Books.

Hays, S. (1996). The cultural contradictions of motherhood. New Havern: Yale University Press. 
Herbst, C. M., \& Ifcher, J. (2012). A bundle of joy: Does parenting really make us miserable? Unpublished http://ssrn.com/abstract=1883839. (13/11/2018).

Hull, E., et al. (2010). Influence of marriage and parenthood on physical activity: A 2-year prospective analysis. Journal of Physical Activity \& Health, 7(5), 577-583.

Hynes, K., \& Clarkberg, M. (2005). Women's employment patterns during early parenthood: A group-based trajectory analysis. Journal of Marriage and Family, 67(1), 222-239.

Janisse, H., Barnett, B., \& Nies, M. (2009). Perceived energy for parenting: A new conceptualization and scale. Journal of Child and Family Studies, 18, 312-322.

Jansen, M., Snoeckx, L., \& Mortelmans, D. (2009). Repartnering and (re)employment: Strategies to cope with the economic consequences of partnership dissolution. Journal of Marriage and the Family, 71, 1271-1293.

Jylhä, M., Guralnik, J. M., Ferrucci, L., Jokela, J., \& Heikkinen, E. (1998). Is self-rated health comparable across cultures and genders? The Journals of Gerontology Series B: Psychological Sciences and Social Sciences, 53(3), S144-S152.

Kalmijn, M., \& Poortman, A. R. (2006). His and her divorce: The gendered nature of divorce and its determinants. European Sociological Review, 22, 201-214.

Kohler, H. P., Behrman, J. R., \& Skytthe, A. (2005). Partner+ children= happiness? The effects of partnerships and fertility on well-being. Population and Development Review, 31(3), 407-445.

Krueger, A., \& Schkade, D. (2008). The reliability of subjective wellbeing measures. Journal of Public Economics, 92, 1853-1845.

Leopold, T. (2018). Gender differences in the consequences of divorce: A study of multiple outcomes. Demography, 55, 1-29.

Leopold, T., \& Kalmijn, M. (2016). Is divorce more painful when couples have children? Evidence from long-term panel data on multiple domains of well-being. Demography, 53(6), 1717-1742.

Lewin, A., \& Stier, H. (2018). Marital status, gender, and material hardship: Evidence from Israel. Advances in Life Course Research, 35, 45-56.

Louis, V. V., \& Zhao, S. (2002). Effects of family structure, family SES, and adulthood experiences on life satisfaction. Journal of Family Issues, 23(8), 986-1005.

Maldonado, L., \& Nieuwenhuis, R. (2015). Family policies and single parent poverty in 18 OECD countries, 1978-2008. Community, Work \& Family, 18(4), 395-415.

McFadden, E., Luben, R., et al. (2009). Self-rated health does not explain the socioeconomic differential in mortality: A prospective study in the EPIC-Norfolk cohort. Journal of Epidemiology and Community Health, 63(4), 329-331.

Meadows, S. O. (2009). Family structure and fathers' well-being: Trajectories of mental health and self-rated health. Journal of Health and Social Behaviour, 50(2), 115-131.

Michaelson, J., Abdallah, S., Steuer, N., \& Thompson, S. A. M. N. (2009). National Accounts of Wellbeing: Bringing real wealth on to the Balance Sheet. London: New Economics Foundation.

Milkie, M. A., Kendig, S. M., Nomaguchi, K. M., \& Denny, K. E. (2010). Time with children, children's well-being, and work-family balance among employed parents. Journal of Marriage and the Family, 72(5), 1329-1343.

Mortelmans, D., Pasteels, I., Van Bavel, J., Bracke, P., Matthijs, K., \& Van Peer, C. (2011). Divorce in Flanders. Data collection and code book [electronic resource]. Retrieved from http://www. divorceinflanders.be. (13/11/2018).

Musick, K., Meier, A., \& Flood, S. (2016). How parents fare: Mothers' and fathers' subjective well-being in time with children. American Sociological Review, 81(5), 1069-1095.

Nomaguchi, K. M., Milkie, M. A., \& Bianchi, S. M. (2005). Time strains and psychological wellbeing: Do dual-earner mothers and fathers differ? Journal of Family Issues, 26(6), 756-792.

OECD. (2013). OECD guidelines on measuring subjective well-being. Paris: OECD Publishing. https://doi.org/10.1787/9789264191655-en. (13/11/2018).

Oksuzyan, A., Crimmins, E., et al. (2010). Cross-national comparison of sex differences in health and mortality in Denmark, Japan and the US. European Journal of Epidemiology, 25(7), $471-480$. 
Pollmann-Schult, M. (2018). Single motherhood and life satisfaction in comparative perspective: Do institutional and cultural contexts explain the life satisfaction penalty for single mothers? Journal of Family Issues, 39(7), 2061-2084.

Reichl, C., Leiter, M. P., \& Spinath, F. M. (2014). Work-nonwork conflict and burnout: A metaanalysis. Human Relations, 67(8), 979-1005.

Ryff, C. D. (2014). Psychological well-being revisited: Advances in the science and practice of Eudaimonia. Psychotherapy and Psychothematics, 83(1), 10-28.

Sanchez, L., \& Thomson, E. (1997). Becoming mothers and fathers: Parenthood, gender, and the division of labor. Gender \& Society, 11(6), 747-772.

Shor, E., Roelfs, D. J., Bugyi, P., \& Schwartz, J. E. (2012). Meta-analysis of marital dissolution and mortality: Reevaluating the intersection of gender and age. Social Science \& Medicine, 75(1), 46-59.

Simon, R. W. (1992). Parental role strains, salience of parental identity and gender differences in psychological distress. Journal of Health and Social Behavior, 33, 25-35.

Singh, I. (2004). Doing their jobs; mothering with ritalin in a culture of mother blame. Social Science and Medicine, 59, 1193-1205.

Stack, S., \& Eshleman, J. R. (1998). Marital status and happiness: A 17-nation study. Journal of Marriage and the Family, 60, 527-536.

Stevenson, B., \& Wolfers, J. (2009). The paradox of declining female happiness. American Economic Journal: Economic Policy, 1(2), 190-225.

Taloyan, M., Leineweber, C., Hyde, M., \& Westerlund, H. (2015). Self-rated health amongst male and female employees in Sweden: A nationally representative study. International Archives of Occupational and Environmental Health, 88(7), 849-859.

Thomson, S., \& Marks, N. (2008). Measuring well-being in policy: Issues and applications. London: New Economics Foundation.

Townsend, N. (2002). The package deal. Marriage, work, and fatherhood in men's lives. Philadelphia: Temple University Press.

Wu, Y., Zhang, D., et al. (2012). Gender-specific patterns in age-related decline in general health among Danish and Chinese: A cross-national comparative study. Geriatric Gerontology International, 12(3), 431.

Open Access This chapter is licensed under the terms of the Creative Commons Attribution 4.0 International License (http://creativecommons.org/licenses/by/4.0/), which permits use, sharing, adaptation, distribution and reproduction in any medium or format, as long as you give appropriate credit to the original author(s) and the source, provide a link to the Creative Commons license and indicate if changes were made.

The images or other third party material in this chapter are included in the chapter's Creative Commons license, unless indicated otherwise in a credit line to the material. If material is not included in the chapter's Creative Commons license and your intended use is not permitted by statutory regulation or exceeds the permitted use, you will need to obtain permission directly from the copyright holder.

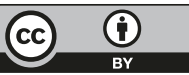

